\title{
DAVIS, MIKE. PLANETA FAVELA. SÃO PAULO: BOITEMPO EDITORIAL, 2006, 272 P. \\ O PERVERSO BOOM URBANO E A FAVELIZAÇÃO DO TERCEIRO MUNDO
}

\author{
Marta Inez Medeiros Marques*
}

Nos próximos anos, pela primeira vez na história da humanidade, o total da população urbana mundial irá sobrepujar o da população rural. Esse fato já pode até ter ocorrido, tendo em vista a imprecisão de alguns censos realizados em países do terceiro mundo. A que se deve esse fenômeno, onde se concentra e como vive a população que hoje se urbaniza?

Planeta favela procura responder a essas questões ao discorrer sobre o crescimento das cidades e da pobreza urbana no terceiro mundo - incluindo a China e países do ex-bloco comunista - e, em particular, sobre a fase mais recente deste processo, caracterizada por sua acentuada aceleração. Nele, Mike Davis analisa os processos gerais relacionados ao "perverso boom urbano" verificado em escala mundial a partir de meados dos anos 1970, utilizando extraordinária bibliografia, majoritariamente em língua inglesa, e inúmeros dados estatísticos, numa perspectiva marxista.

O livro foi publicado no Brasil pela Boitempo apenas poucos meses depois do lançamento de sua versão original pela Editora Verso, Londres/Nova York, em março de 2006. Esse fato se deve seguramente à atualidade e relevância da temática tratada, além da acolhida que ela encontra no meio acadêmico e na opinião pública brasileiros. A pobreza urbana tem sido alvo da atenção de nossos políticos, intelectuais e jornalistas desde fins do século XIX, além de objeto de estudos e pesquisas em diferentes áreas do conhecimento, especialmente nas ciências sociais, desde meados do século XX. Dentre a produção mais recente sobre o tema, destacam-se os trabalhos da socióloga Licia Valladares $(2005)^{1}$, dos antropólogos Alba Zaluar e Marcos Alvito $(1998)^{2}$ e dos geógrafos Jailson de Souza e Jorge Luiz Barbosa (2005) ${ }^{3}$, dentre outros.

A idéia do livro de Davis nasceu do artigo "Planeta de favelas: a involução urbana e o proletariado informal", publicado na New Left Review (número 26, de março/abril de 2004, p.5$34)^{4}$ e escrito sob o impacto do Relatório Global sobre Assentamentos Humanos de 2003: a ameaça das favelas, do Programa UN-HABITAT das Nações Unidas.

De acordo com esse relatório, a população urbana, atualmente cerca de 3,2 bilhões de pessoas, deve alcançar a cifra de 10 bilhões em 2050, concentrando-se sobretudo em metrópoles situadas no hemisfério sul, o que representa uma escala e uma velocidade impressionantes do processo de urbanização. O documento apresenta um censo global das favelas e avalia que, a continuar a atual tendência, a população residente em favelas, um total de 924 milhões de pessoas, cerca de um terço da população urbana mundial em 2001, atingirá o número de cerca de 2 bilhões nos próximos 30 anos. Ao mesmo tempo, prevê que a população rural começará a decrescer em números absolutos a partir de 2020.

Desde o encontro do UN-HABITAT de Nairóbi em 2002, as Nações Unidas adotam 
oficialmente uma definição operacional de favela que se restringe às suas características físicas e legais. Ou seja, para a ONU, favela é uma área superpovoada, pobre ou com residências informais, acesso inadequado a água potável e condições sanitárias e posse insegura. Apesar de considerar a definição da ONU restritiva e conservadora por deixar de fora uma parcela significativa da população geralmente considerada por especialistas como favelada, Davis reconhece a dificuldade de se obter dados precisos sobre o fenômeno, muitas vezes deliberadamente subestimado em estatísticas oficiais.

Para Davis a principal causa do "Big Bang da pobreza urbana" foi a imposição de Programas de Ajuste Estrutural do Banco Mundial-FMI aos países endividados e os choques econômicos que aconteceram a partir dos anos 1980. Esses programas são responsáveis pela eliminação de subsídios a pequenos produtores rurais e pela exposição crescente de seus produtos à concorrência, num mercado dominado pela produção do agronegócio do primeiro mundo, altamente subsidiado. Estes programas também estimularam o avanço do processo de privatização em várias frentes, o encolhimento do setor público etc. Para Davis, as cidades têm simplesmente colhido os resultados da crise agrária mundial desencadeada por essas políticas e a favela se torna o destino implacável não apenas para os migrantes rurais pobres, mas também para milhões de habitantes urbanos tradicionais, deslocados ou fortemente empobrecidos pelo impacto das medidas de ajuste estrutural que favorecem o avanço da ordem neoliberal e o aumento da desigualdade de renda entre os países mais ricos e os mais pobres.

Esses processos são destacados em contraposição com o que ocorreu no período anterior, quando o crescimento urbano e a proliferação de bairros populares - nos limites da lei e fora da proteção do Estado - no Terceiro Mundo aconteceu num cenário de expansão da indústria substitutiva de importações ou de processos de independência em ex-colônias. Nesse período, a esperança de dias melhores dava o tom geral dos ânimos, o que foi sendo pouco a pouco alterado, com o descumprimento de suas promessas e a "traição" do Estado, que contribui de forma ativa para a recriação continuada de padrões de segregação urbana com suas políticas de zoneamento, modernização e embelezamento da cidade. Em inúmeros casos, o Estado chega a usar a força para impor uma orientação geral ao crescimento da cidade, em conformidade com os interesses dos grupos no poder.

Além disso, o crescimento dos empréstimos destinados a programas de desenvolvimento urbano do Banco Mundial deu a essa instituição um amplo poder de influência sobre a concepção e implementação de políticas urbanas nacionais. Mesmo as áreas de fronteira urbana, situadas nas "bordas" da cidade, vão sendo tomadas pela expansão da cidade formal, em ciclos de assentamento, expulsão e reassentamento. Nesse contexto, as ações comunitárias de auto-ajuda e o imperialismo "soft" das ONG's, cativas das agendas dos principais organismos de financiamento internacional, podem alcançar sucesso pontual, mas deixam ao desabrigo a vasta maioria dos pobres. Estado, ONG's, Associações de Moradores e Instituições Internacionais parecem "patinar" na resolução das questões surgidas desse conflito, atuando apenas no sentido de aplacar as tensões por meio de medidas localizadas.

O livro trata de questões relativas ao espaço e ao uso da terra nas favelas e de questões referentes à economia informal. São analisados criticamente alguns mitos referentes à economia informal, dentre outros, aqueles decorrentes de uma visão romântica e utópica do setor, que o encara como algo próximo a uma economia urbana de subsistência. Ele analisa as características atuais do processo de proletarização com a constituição de uma vasta população sobrante e as estratégias desenvolvidas pelas famílias pobres para enfrentar as mudanças na economia e 

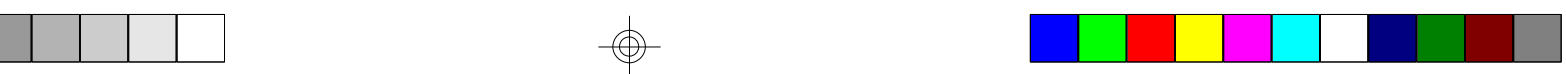

assegurar sua reprodução social, com um aumento significativo do trabalho da mulher. 0 livro trata ainda da ecologia ou lugar onde são geralmente encontradas as favelas - terras menos valorizadas, locais de risco, áreas de preservação, fronteira urbano-rural e destaca que a pobreza magnifica os riscos e acidentes geológicos e climáticos que ocorrem nessas áreas.

Também são abordados problemas específicos relacionados à população pobre residente em grandes cidades do Terceiro Mundo, nos diferentes continentes. Alguns casos mencionados chamam a atenção por sua crueza e dramaticidade como o das crianças acusadas de feitiçaria, expulsas de casa e abandonadas nas ruas de Kinshasa no Zaire; a exportação de órgãos humanos em favelas da Índia e Egito; ou os grandes constrangimentos desencadeados pelo enorme déficit de equipamentos sanitários e a necessidade de uso de espaços públicos para defecar em Deli na Índia, levando a uma elevada tensão entre classes e à luta pelo "direito de defecar".

A obra de Davis constitui uma leitura importante para o público brasileiro, por permitir uma melhor contextualização das origens de nossa pobreza urbana e sua relação com processos sociais verificados em escala global. Contribui, assim, para a superação de uma visão, bastante difundida entre nós, que atribui a extrema desigualdade social que nos caracteriza exclusivamente a processos de ordem interna, como as ações de nossas elites autoritárias e de um Estado patrimonialista e cronicamente ineficiente.

Porém, como qualquer obra, Planeta Favela também apresenta limitações. Davis reconhece a complexidade da problemática da pobreza urbana, que pode se apresentar de diferentes formas e estar relacionada a uma diversidade de questões políticas, econômicas e sociais. Contudo, apesar de não reproduzir a visão preconceituosa de certos autores conservadores, a sua análise não supera uma leitura dual da cidade. Em estilo vigoroso, envolvente e em tom de indignação, ele descreve a acelerada urbanização do Terceiro Mundo como um processo marcado pela formação de áreas onde se concentram decadência, desestruturação social e desesperança, mas nos diz pouco sobre a cidade em sua totalidade e como as favelas a ela se integram.

O termo slum adotado na versão inglesa, está associado na sua origem à idéia de degradação humana, área caracterizada por casas dilapidadas, superpopulação, doença, pobreza e vício, ou seja, o lado obscuro da cidade, onde vive uma população esquálida e criminosa, o resíduo social. Apesar de suas especificidades histórico-geográficas, a favela, termo empregado em lugar de slum na tradução para o português, também corresponde a uma área da cidade caracterizada por suas carências e/ou atributos negativos.

Em seu projeto ambicioso de traçar um amplo panorama da realidade atual das favelas no Terceiro Mundo e buscar explicações gerais, Davis não examina devidamente processos que ajudariam a compreender como esse fenômeno se manifesta em contextos histórico-geográficos específicos. Na tentativa de atenuar esta deficiência, a edição da Boitempo traz um posfácio da urbanista Erminia Maricato que dialoga com a obra de Davis e recupera momentos e faces significativos da história urbana brasileira. A autora ressalta a necessidade de descermos às contradições da realidade próxima e considerarmos os diferentes agentes envolvidos no processo de produção do espaço das favelas para aprofundarmos a nossa compreensão sobre o fenômeno e, numa postura otimista, enumera algumas conquistas alcançadas pelos movimentos sociais urbanos nas últimas décadas.

Davis abre o livro com uma epígrafe de Patrick Geddes que afirma ter a favela, semifavela ou superfavela se tornado a evolução da cidade. Todos os seus argumentos parecem convergir para a confirmação desse prognóstico para os países do Terceiro Mundo. Ele chama a 
atenção para o fato de que a urbanização tem avançado independentemente da industrialização e de quaisquer perspectivas de desenvolvimento, demonstrando que a constituição de um modo de produção urbano-industrial não pode mais ser visto como o resultado natural da transformação do modo de produção rural-agrário sob o capitalismo. As metrópoles do Terceiro Mundo são demograficamente dinâmicas, porém, pobres em postos de trabalho formais.

Nesses casos, em que o tamanho da economia de uma cidade apresenta pouca relação com o tamanho de sua população, temse observado a proliferação de atividades informais caracterizadas, em grande parte, pela intensificação do processo de trabalho com retorno marginal decrescente, similar ao que Geertz (1969) denominou de involução agrícola ao estudar a rizicultura na Indonésia. Davis se inspira em Geertz e afirma que a importância crescente dessas atividades informais na economia urbana caracterizaria um processo de involução urbana, o que, vale ressaltar, nada tem a ver com o que Santos (1993) denomina de involução metropolitana ${ }^{5}$.

A referência ao termo involução revela uma contradição entre a forma como o fenômeno urbano se apresenta na contemporaneidade e - conteúdo atribuído ao processo de urbanização pelas utopias modernas, que o viam como expressão do avanço das forças produtivas e do progresso. Também sugere uma dificuldade por parte do autor, comum entre os marxistas, de lidar com essa contradição e de escapar de uma abordagem linear da história, denunciada pelos próprios termos da epígrafe acima referida. Ou seja, se a produção urbanoindustrial não é mais o resultado natural das mudanças nas sociedades agrárias na atualidade, as favelas e o trabalho informal intensivo parecem sê-lo.

Para superar tanto a tendência a uma excessiva generalização como a uma leitura linear da história, uma alternativa possível é seguir Harvey (2006) em sua adesão a uma versão da dialética que enfatiza as relações internas e negocia continuamente a relação entre o particular e o universal, entre o abstrato e o concreto. A diversidade de situações descritas por Davis para retratar as diferentes formas em que a pobreza urbana pode aparecer bem mereceria uma maior reflexão teórica, visando apreender as múltiplas determinações da pobreza urbana e a dinâmica resultante da reunião e interação entre os diferentes processos em jogo em sua distribuição geográfica desigual, contribuindo para a construção de uma teoria do desenvolvimento geográfico desigual do capitalismo.

Davis encontra explicações para o fenômeno analisado na globalização neoliberal. Na visão de Harvey (2006), o neoliberalismo é engendrado como resposta das elites à atual crise de sobreacumulação do capitalismo, que impõe a desvalorização de ativos e o avanço da acumulação por espoliação para abrir caminho para novos ciclos de investimento e a acumulação com base na reprodução ampliada, o que tem resultado na ampla difusão de formas de expropriação e privatização sobre a terra e os recursos naturais, afetando profundamente a teia da vida e as bases materiais da reprodução social.

Assim, poderíamos relacionar o acelerado crescimento da pobreza urbana a esse processo mais amplo, relacionado ao movimento geral do capitalismo marcado por ciclos e crises de sobreacumulação. Porém, a crise atual parece mais profunda na medida em que o potencial disruptivo do capitalismo alcança níveis inimagináveis, comprometendo a sobrevivência do planeta e esgarçando ao extremo o tecido social em muitos lugares, o que pode ter efeitos explosivos.

Os movimentos sociais hoje têm sido motivados sobretudo por disputas envolvendo o acesso à terra e aos recursos naturais, ou por condições mínimas necessárias para a reprodução social, a reprodução da vida. A produção da cidade é resultado de todos esses processos e também dessas lutas. O próprio Davis nos alerta para a 

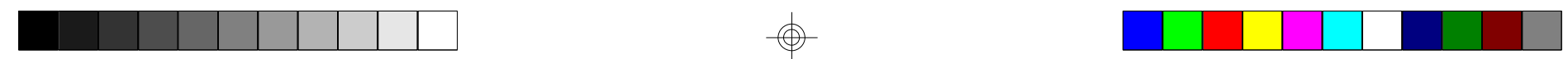

crescente preocupação das elites e seus intelectuais com a violência urbana e o potencial de insurgência dos pobres urbanos, bem como para as implicações geopolíticas do crescimento acelerado da pobreza urbana, o que tem levado o Pentágono a discutir guerra urbana e a desenvolver estudos sobre operações militares em terrenos urbanos.

Planeta favela nos leva a vislumbrar um futuro para a humanidade marcado pela decadência e constituído por massas humanas amontoadas em espaços marginais e sem lugar nos circuitos dominantes da economia mundial. Diante de um cenário tão sombrio, o que nos resta a fazer? Como o autor revela ao final do texto que atualmente está redigindo em parceria com Forrest Hylton ${ }^{6}$ um livro que corresponde à seqüência deste, em que irá tratar da história e futuro da resistência vinda das favelas ao capitalismo global, vale a pena conferir para ver quais pistas ele tem a nos dar sobre o assunto.

\section{Notas}

1 A invenção da favela: do mito de origem a favela.com, no qual é feita uma sociologia da sociologia da favela e trata-se das representações sociais dominantes sobre o tema do final do século XIX aos dias de hoje.

2 Um século de favela, que reúne um conjunto de artigos representativos da produção antropológica sobre o tema na atualidade.

3 Favela: alegria e dor na cidade, que procura desfazer mitos sobre a favela, construídos a partir do paradigma da ausência. Seus autores chamam atenção para o fato de que as favelas são sempre definidas como local da pobreza, da falta de perspectiva, a partir do que não têm, e afirmam que é preciso construir um novo olhar a partir do paradigma da presença, ou seja, considerando o que a favela tem.
4 Este artigo também pode ser encontrado em Contragolpes (2006).

5 Segundo Santos (1993), o processo de involução metropolitana, em contraposição ao de metropolização, ocorre quando passam a crescer não somente algumas poucas grandes cidades, mas também as cidades médias e locais criando um verdadeiro "exército industrial de reserva de lugares", com a proliferação de uma enorme quantidade de lugares propícios ao exercício dos capitais hegemônicos, permitindo a fragmentação do território e uma nova divisão social e territorial do trabalho.

${ }^{6}$ Especialista em urbanismo latino americano.

\section{Bilbiografia}

GEERTZ, Clifford. Agricultural Involution: the processes of ecological change in Indonesia. 2 ed. Berkeley: University of California Press, 1969.

HARVEY, David. Spaces of Global Capitalism: towards a theory of uneven geographical development. London/New York: Verso, 2006.
SADER, Emir (org.). Contragolpes: seleção de artigos da New Left Review. São Paulo: Boitempo Editorial, 2006

SANTOS, Milton. A urbanização brasileira. São Paulo: Hucitec, 1993.

UN-HABITAT. The challenge of slums: global report on human settlements 2003. 2 ed. London: Earthscan, 2006 
